\title{
Factors associated with high psychological distress in primary carers of people with disability
}

Jiali Wang, Wei Du

\section{Background \\ Primary caregivers of people with disability provide extensive physically and emotionally demanding care.}

\section{Objectives}

The aim of this study was to quantify the burden of high psychological distress in primary carers of people with disability and identify modifiable factors in relation to high psychological distress.

\section{Methods}

The 2015 national 'Survey of Disability, Ageing and Carers in Australia' was used to derive a nationally representative sample and estimate weighted prevalence rates of high psychological distress (Kessler scores $\geq 22$ ) in primary carers of people with disability. Risk factors were evaluated using weighted logistic regression models with lasso techniques.

\section{Results}

Approximately $27 \%$ of carers had high psychological distress. Nearly half of the study population reported changes in their health and wellbeing. A delay in general practitioner (GP) visits was common and associated with $>2$-fold increase in risk of high psychological distress.

\section{Discussion}

The findings suggest targets for early diagnosis and intervention, and adequate referrals from GPs to meet the health needs of carers.
IN AUSTRALIA, there are 856,000 primary caregivers providing extensive informal care in terms of assistance to people with disability in daily activities such as eating and showering. ${ }^{1}$ The total replacement cost, defined as the total value that would need to be diverted from the formal economy to replace the services provided by informal carers, has been estimated to reach $\$ 60$ billion a year. ${ }^{2}$ However, extensive informal caregiving is a stressor for many people who are caring for people with disability, ${ }^{3}$ and it is associated with increased all-cause mortality risks when compared with their non-caregiving counterparts. ${ }^{4}$ Poorer psychological health has been observed among primary carers. ${ }^{3}$

Identification of primary carers with different characteristics and needs is crucial to inform mental health services for providing appropriate care. ${ }^{5}$ Psychological distress, a well-established measure reflecting complicated personenvironment elements, is useful for informing mental health services and intervention strategies. ${ }^{6}$ However, empirical research to assess prevalence rates and investigate modifiable risk factors in the general population is limited. Using a nationally representative survey, the aim of this study was to quantify the burden of high psychological distress among primary carers of people with disability, and further explore its association with individual and contextual factors. Findings may inform family-centred and person-centred mental healthcare services and policies in similar settings.

\section{Methods}

The 2015 national 'Survey of Disability, Ageing and Carers (SDAC) in Australia' was sourced from the Australian Bureau of Statistics (ABS). Using multistage sampling schemes, the ABS conducted the 2015 SDAC with strict quality control measures to ensure survey coverage, reliability and confidentiality to derive a nationally representative sample. ${ }^{7}$ It comprised rich individual demographic, socioeconomic and contextual environmental information for primary carers of people with disability. ${ }^{8}$ Additional approval for the current study was granted by the Australian National University Human Research Ethics Committee (Reference: 2017/175).

\section{Study population and outcome}

The study outcome was psychological distress. It was measured by the Kessler Psychological Distress Scale (K10), ${ }^{6}$ which was further categorised as high (K10 scores $\geq 22$ ) or low (K10 scores $<22$ ) to differentiate high level of distress with clinical significance. By considering all primary carer respondents aged $\geq 18$ years living in households (ie private dwellings and self-care retirement villages), ${ }^{9}$ and excluding those without K10 responses 
$(\mathrm{n}=83)$, the final study population comprised 2338 primary carers of people with disability.

\section{Exposure variables}

The Anderson-Newman behavioural model was used, comprising constructs in relation to sociology, psychology and healthcare, as the conceptual basis for understanding factors associated with high psychological distress. ${ }^{10}$ The lasso regularisation technique was applied to enhance variable selection and model interpretation. ${ }^{11}$ The variables selected by lasso models were further entered into the confirmatory logistic regression model.

\section{Statistical analysis}

R software (version 3.3.1) was used to carry out all analyses with the ABS-provided sample and replicate weights to reflect complex sampling design. Weighted numbers and proportions were calculated using different population characteristics, as well as prevalence rates of high psychological distress in the study population. The 'glmnet' package was first used to run lasso models performing variable selection in the presence of multicollinearity. ${ }^{11}$ Multivariable logistic regression was then performed using the 'survey' package to estimate odds ratios (ORs) and 95\% confidence intervals (CIs) for high psychological distress in relation to the selected explanatory variables. $P$ values $<0.05$ were considered to be statistically significant.

\section{Results}

The study population comprised a weighted total of 800,000 adult carers living in households and providing informal care to people with disability in Australia. Of these 2338 primary carers, the majority were aged $45-64$ years (45\%), female (68\%), married (66\%), concession card holders (59\%; Table 1). The majority of the study population (91\%) needed to see a general practitioner (GP) in the past 12 months; however, fewer than one-third (31\%) delayed seeing a GP, suggesting a higher likelihood of increased distress due to such unmet needs. Approximately $38 \%$ of primary carers in the study population had long-term conditions (eg musculoskeletal disease, cancer or mental disorder lasting for $\geq 6$ months with specific restriction), ${ }^{12}$ $22 \%$ had stress-related illness, and 56\% had their relationship with the main recipient of care affected due to their caring role.

Approximately $27 \%$ of primary carers had high psychological distress (95\% CI: 25\%, 28\%). The weighted prevalence of high psychological distress decreased with age and educational attainment (Table 1 ). Primary carers who delayed seeing a GP or dental professional or going to hospital had high psychological distress. Nearly half of the primary carers' physical or emotional wellbeing had changed due to their caring role, one-third of whom had high psychological distress.

Female carers were $46 \%$ more likely to have high psychological distress than males (adjusted OR [AOR]: 1.46; 95\% CI: 1.11, 1.92; Table 1). Having long-term conditions (AOR: 2.40, 95\% CI: 1.86, 3.09) or stress-related conditions (AOR: 2.60; 95\% CI: 1.76, 3.84) or delaying GP consultations (AOR: 2.44 ; 95\% CI: 1.22, 4.87) was significantly associated with an increase in odds of high psychological distress. The risk decreased with age, educational attainment and participation in social activities. Caring for individuals who had high psychological distress or musculoskeletal conditions was significantly associated with high psychological distress in their primary carers, whereas caring for individuals without problem behaviours was associated with a one-third reduction in the odds of high psychological distress (AOR: 0.63; 95\% CI: 0.44, 0.90). When the relationship between primary carers and the main recipient of care was closer, the odds of high psychological distress were elevated by $50 \%$ in primary carers (AOR: 1.50; 95\% CI: 1.22, 2.00).

\section{Discussion}

On the basis of the latest nationally representative data, the prevalence of high psychological distress in primary carers $(27 \%)$ of people with disability was almost three times higher than that in the general population (11\%). ${ }^{13}$ Delayed healthcare was common in the study population. For example, about one-third of primary carers (31\%) delayed seeing a GP, an approximate increase of $15 \%$ over the general population (27\%). ${ }^{14}$ This was associated with an elevated risk of high psychological distress, suggesting a potential target for developing intervention strategies to improve mental health in these carers. This empirical study adds to the growing body of evidence with regard to provision of appropriate healthcare to meet carers' own health needs in this vulnerable group.

Caregiving is never stress-free, especially when carers themselves have long-term conditions, ${ }^{15}$ or when they are taking care of people with disability ${ }^{3}$ or recipients with psychological needs. ${ }^{16}$ It was noted that $47 \%$ of primary carers reported a change in their health and wellbeing due to their caring role (Table 1), leading to a significant increase in the risk of high psychological distress. This could be due to a number of factors. For example, they might not look after themselves because of the high level of involvement in taking care of their recipients, or their caring duties may have restricted social and leisure activities. ${ }^{16}$ Other constraints such as time and financial income could also affect carers. ${ }^{17}$ Given the complexity and demanding nature of taking care of people with disability, carers are exposed to possible emotional exhaustion in the long term, which may warrant clinical attention. ${ }^{18}$ It is therefore important for GPs to recognise any potential deteriorating physical and/or emotional health of carers, and take early action in response to their healthcare needs.

Given GPs are the main access point for primary healthcare services, it is likely the vast majority of interventions for carers' psychological distress would not involve psychiatrists, but would be provided by GPs and allied health professionals. ${ }^{19,20}$ GPs' knowledge of mental health conditions and treatment, and their relationships with psychiatrists, can affect the provision of appropriate 
mental health support in primary healthcare settings. For example, GPs with mental health training have shown improvements in mental healthcare during consultations. ${ }^{21}$ Therefore, greater awareness and early diagnosis and intervention of high psychological distress in GPs, as well as better coordination between GPs and psychiatrists, may have the potential to improve psychological wellbeing in primary carers.

This study used large-scale nationally representative data and presented reliable prevalence estimates of high psychological distress in carers of people with disability, allowing national comparisons with other countries of similar settings. However, the cross-sectional nature of SDAC data precludes inference to establish causal pathways. For example, it was not possible to determine whether participation in social activities had taken place with or without the care recipient. Caution is clearly required when interpreting results. Further prospective study of these factors on carers' mental health is warranted. Moreover, bias may arise partly as a result of errors in self-reporting and data collection. The ABS has implemented standardised quality control measures at all stages of data processing, including careful design and testing of questions, interviewer training and respondent follow-up. ${ }^{7}$ The current results can therefore be considered robust and provide evidence to inform policy and practice strategies required to reduce high psychological distress in primary carers of people with disability.

\section{Implications for general practice}

Regular mental health skill-building with evidence-based updates on risk and resilience factors is conducive to increasing GPs' confidence in dealing with carers' distress. Practices could take proactive approaches to screen and assess carers at increased risk of high psychological distress, and start interventions to support these carers. One opportunity for screening and assessment may be when care recipients are attending a general practice appointment.

\section{Authors}

Jiali Wang PhD, postdoctoral fellow, Data61, CSIRO, Canberra. jiali.wang@data61.csiro.au

Wei Du PhD, Epidemiologist and biostatistician, Research School of Population Health, Australian National University, Canberra

\section{Acknowledgements}

We would like to thank the Australian Bureau of Statistics for providing the Confidentialised Unit Record Files (CURF) product - the 2015 Survey of Disability, Ageing and Carers.

Competing interests: None.

Funding: None.

Provenance and peer review: Not commissioned, externally peer reviewed.

\section{References}

1. Australian Bureau of Statistics. Disability, ageing and carers, Australia: Summary of findings, 2015 - Key findings. Canberra: ABS, 2016. Available atwww.abs.gov.au/ausstats/abs@. nsf/Latestproducts/4430.0Main\%20Features 12015? opendocument\&tabname $=$ Summary\&pr odno $=4430$. 0 \&issue $=2015 \&$ num $=\& v i e w=$ [Accessed 5 November 2018].

2. Carers Australia. The economic value of informal care in Australia in 2015. Canberra: Carers Australia, 2015

3. Edwards B, Gray M, Zmijewski N, Kingston M. The nature and impact of caring for family members with a disability in Australia: Research report no 16. Melbourne: Australian Institute of Family Studies, 2008.

4. Schulz R, Beach S. Caregiving as a risk factor for mortality: The Caregiver Health Effects Study. JAMA 1999;282(23):2215-19.

5. Hewlett E, Moran V. Making mental health count: The social and economic costs of neglecting mental health care. Paris: OECD Publishing, 2014.

6. Andrews G, Slade T. Interpreting scores on the Kessler Psychological Distress Scale (K10). Aust N Z J Public Health 2001;25(6):494-97.

7. Australian Bureau of Statistics. Disability, ageing and carers, Australia: Summary of findings, 2015 - Quality declaration: Summary. Canberra: Australian Bureau of Statistics, 2016. Available at www.abs.gov.au/ Ausstats/abs@.nsf/0 /0CD3AF801A5AF10 8CA25804F000F61FB?OpenDocument [Accessed 5 November 2018].

8. Australian Bureau of Statistics. Survey of disability, aging and carers (SDAC): Household survey questionnaire. Canberra: ABS, 2015. Available at: www.ausstats.abs.gov.au/ausstats/subscriber. nsf/0/8F411A618C3CD63DCA25804F000F60 CD/\$File/attk7lrm.pdf [Accessed 5 November 2018]

9. Australian Bureau of Statistics. Disability, ageing and carers, Australia: Summary of findings, 2015 - Explanatory notes. Canberra: ABS, 2016 Available at www.abs.gov.au/AUSSTATS/abs@. nsf/Latestproducts/4430.0Explanatory\%20 Notes12015?opend ocument\&tabname $=$ Note s\&prodno $=4430.0$ \&issue $=2015 \&$ num $=\& v i e w=$ [Accessed 5 November 2018].

10. Andersen R, Newman J. Societal and individual determinants of medical care utilization in the United States. Milbank Mem Fund Q Health Soc 1973;51(1):95-124.

11. Tibshirani R. Regression shrinkage and selection via the lasso. J R Stat Soc Ser B Stat Methodol 1996;58(1):267-88.
12. Australian Bureau of Statistics. National health survey: Users' guide, 2014-15 - Long-term conditions. Canberra: ABS, 2017. Available at: www.abs.gov.au/ausstats/abs@.nsf/Lookup/ by\%20Subject/4363.0 2014-15 Main\%20 Features Long-term\%20Conditions\%20(Other) 31 [Accessed 5 November 2018].

13. Australian Bureau of Statistics. Profiles of health, Australia, 2011-13. Canberra: ABS, 2012. Available at: www.abs.gov.au/ausstats/abs@.nsf/ Lookup/4338.0main+features42011-13 [Accessed 5 November 2018].

14. Royal Australian College of General Practitioners. Health of the nation, 2017. East Melbourne: RACGP, 2017. Available at: www.racgp.org.au/ yourracgp/news/media-releases/seeing-yourregular-gp-critical-to-the-health-of-the-nation [Accessed 5 November 2018].

15. Darragh A, Sommerich C, Lavender S, Tanner KJ, Vogel K, Campo M. Musculoskeletal discomfort, physical demand, and caregiving activities in informal caregivers. J Appl Gerontol 2015;34(6):734-60. doi: 10.1177/0733464813496464.

16. Shah AJ, Wadoo O, Latoo J. Psychological distress in carers of people with mental disorders. Br J Med Pract 2010;3(3):a327.

17. Kim D. Relationships between caregiving stress, depression, and self-esteem in family caregivers of adults with a disability. Occup Ther Int 2017;1686143. doi: 10.1155/2017/1686143.

18. Cummins R, Hughes J, Tomyn A, Gibson A, Woerner J, Lai L. Wellbeing of Australians: Carer health and wellbeing. Geelong: Deakin University, 2007.

19. Thompson A, Hunt C, Issakidis C. Why wait? Reasons for delay and prompts to seek help for mental health problems in an Australian clinical sample. Soc Psychiatry Psychiatr Epidemiol 2004;39(10):810-17.

20. Fleury, MJ, Bamvita, JM, Tremblay J. Variables associated with general practitioners taking on serious mental disorder patients. BMC Fam Pract 2009;10(1):41. doi: 10.1186/1471-2296-10-41.

21. Lam TP, Sing Sun K, Piterman L, et al. Impact of training for general practitioners on their menta health services: The Hong Kong experience. Aust J Gen Pract 2018;47(8):550-55. 
Table 1. High psychological distress in primary carers of people with disabilities (sample number and proportion; weighted prevalence rates, adjusted odds ratios, and $95 \%$ confidence intervals)

Variables

Predisposing factors, reflecting demographic and social contextual composition

Age group (years)

\begin{tabular}{|c|c|c|c|c|}
\hline$\leq 44$ & 625 & $28 \%$ & $0.34(0.30,0.38)$ & \\
\hline $45-64$ & 1,032 & $45 \%$ & $0.26(0.23,0.29)$ & $0.81(0.57,1.16)$ \\
\hline $65-84$ & 643 & $26 \%$ & $0.20(0.17,0.23)$ & $0.53(0.35,0.82)$ \\
\hline$\geq 85$ & 38 & $2 \%$ & $0.12(0.03,0.38)$ & $0.33(0.07,1.58)$ \\
\hline Australia & 1,722 & $73 \%$ & $0.27(0.25,0.29)$ & \\
\hline Mainly English speaking countries & 240 & $10 \%$ & $0.18(0.13,0.24)$ & $0.69(0.45,1.06)$ \\
\hline Married & 1,534 & $66 \%$ & $0.23(0.21,0.25)$ & \\
\hline Separated & 102 & $4 \%$ & $0.33(0.24,0.44)$ & $0.75(0.38,1.50)$ \\
\hline Divorced & 236 & $10 \%$ & $0.33(0.27,0.39)$ & $1.15(0.76,1.75)$ \\
\hline Widowed & 75 & $3 \%$ & $0.24(0.15,0.37)$ & $0.98(0.53,1.82)$ \\
\hline Never married & 391 & $17 \%$ & $0.36(0.30,0.42)$ & $1.48(1.03,2.13)$ \\
\hline Bachelor or postgraduate & 724 & $31 \%$ & $0.23(0.19,0.26)$ & \\
\hline Diploma or certificate & 518 & $23 \%$ & $0.26(0.23,0.30)$ & $1.06(0.74,1.52)$ \\
\hline High school & 842 & $35 \%$ & $0.28(0.25,0.32)$ & $1.33(0.93,1.90)$ \\
\hline Did not finish high school & 208 & $9 \%$ & $0.31(0.25,0.39)$ & $1.86(1.11,3.12)$ \\
\hline Unclassifiable & 46 & $2 \%$ & $0.33(0.20,0.50)$ & $1.77(0.82,3.82)$ \\
\hline \multicolumn{5}{|l|}{ Housing tenure } \\
\hline Outright owner & 942 & $40 \%$ & $0.21(0.19,0.23)$ & \\
\hline Owner & 662 & $29 \%$ & $0.25(0.22,0.29)$ & $1.25(0.95,1.65)$ \\
\hline Renter & 605 & $25 \%$ & $0.38(0.34,0.41)$ & $1.35(0.97,1.90)$ \\
\hline Unclassifiable & 129 & $6 \%$ & $0.26(0.17,0.37)$ & $0.85(0.42,1.73)$ \\
\hline \multicolumn{5}{|l|}{ Remoteness of residence } \\
\hline \multicolumn{5}{|c|}{ Saw $\geq 3$ health professionals for the same condition in past 12 months } \\
\hline No & 1,823 & $79 \%$ & $0.23(0.21,0.25)$ & \\
\hline Yes & 515 & $21 \%$ & $0.40(0.36,0.45)$ & $1.33(0.98,1.80)$ \\
\hline \multicolumn{5}{|l|}{ Saw GP in past 12 months } \\
\hline No need & 200 & $9 \%$ & $0.15(0.10,0.21)$ & \\
\hline Delayed due to cost & 144 & $6 \%$ & $0.53(0.44,0.63)$ & $2.44(1.22,4.87)$ \\
\hline Delayed due to other reasons & 569 & $25 \%$ & $0.40(0.36,0.45)$ & $2.09(1.18,3.70)$ \\
\hline When needed & 1,425 & $60 \%$ & $0.20(0.18,0.22)$ & $1.10(0.65,1.86)$ \\
\hline \multicolumn{5}{|c|}{ Saw a dental professional in past 12 months } \\
\hline No need & 843 & $37 \%$ & $0.24(0.21,0.27)$ & \\
\hline Delayed due to cost & 416 & $18 \%$ & $0.42(0.37,0.47)$ & $1.21(0.88,1.65)$ \\
\hline Delayed due to other reasons & 242 & $10 \%$ & $0.33(0.26,0.41)$ & $1.17(0.75,1.81)$ \\
\hline When needed & 837 & $36 \%$ & $0.20(0.16,0.24)$ & $0.92(0.64,1.32)$ \\
\hline \multicolumn{5}{|l|}{ Went to hospital in past 12 months } \\
\hline No need & 1,850 & $80 \%$ & $0.23(0.21,0.26)$ & \\
\hline Delayed due to cost & 13 & $1 \%$ & $0.66(0.32,0.89)$ & $3.97(0.72,21.99)$ \\
\hline Delayed due to other reasons & 40 & $2 \%$ & $0.69(0.48,0.84)$ & $2.26(0.85,6.01)$ \\
\hline When needed & 435 & $18 \%$ & $0.35(0.30,0.40)$ & $1.48(1.08,2.02)$ \\
\hline
\end{tabular}


Table 1. High psychological distress in primary carers of people with disabilities (sample number and proportion; weighted prevalence rates, adjusted odds ratios, and $95 \%$ confidence intervals) (cont'd)

Variables

Enabling factors, reflecting individual perception and experience of their own health and care (cont'd)

Whether primary carer usually assists main recipient of care to manage behaviour

\begin{tabular}{|c|c|c|c|c|}
\hline Usually & 1,350 & $57 \%$ & $0.32(0.29,0.34)$ & \\
\hline Not usually & 716 & $30 \%$ & $0.17(0.14,0.20)$ & $0.63(0.44,0.90)$ \\
\hline Not stated & 272 & $12 \%$ & $0.27(0.22,0.33)$ & $0.65(0.13,3.24)$ \\
\hline \multicolumn{5}{|c|}{ Main effect of caring role on primary carer's relationship with main recipient of care } \\
\hline Unaffected & 728 & $31 \%$ & $0.18(0.15,0.21)$ & \\
\hline Strengthened & 893 & $38 \%$ & $0.29(0.25,0.32)$ & $1.50(1.12,2.00)$ \\
\hline Strained & 438 & $18 \%$ & $0.35(0.31,0.40)$ & $1.43(0.97,2.10)$ \\
\hline Not stated & 279 & $13 \%$ & $0.29(0.24,0.35)$ & $2.34(0.49,11.25)$ \\
\hline \multicolumn{5}{|c|}{ Whether participated in physical activities for sport, away from home, in past 12 months } \\
\hline No & 1,863 & $79 \%$ & $0.29(0.27,0.31)$ & \\
\hline Yes & 475 & $21 \%$ & $0.17(0.14,0.22)$ & $0.70(0.49,1.01)$ \\
\hline \multicolumn{5}{|c|}{ Whether attended any sporting events as a spectator in past 12 months } \\
\hline No & 1,744 & $74 \%$ & $0.29(0.27,0.31)$ & \\
\hline Yes & 594 & $26 \%$ & $0.19(0.16,0.22)$ & $0.64(0.46,0.90)$ \\
\hline
\end{tabular}

Need factors, reflecting individual perceived needs for health and care Whether primary carer has had a stress-related illness due to caring role

No

Yes

$1,834 \quad 78 \% \quad 0.23(0.21,0.25)$

$504 \quad 22 \% \quad 0.40(0.35,0.45)$

$2.60(1.76,3.84)$

Whether primary carer has a long-term condition

\begin{tabular}{|c|c|c|c|c|}
\hline No & 1416 & $62 \%$ & $0.18(0.16,0.20)$ & \\
\hline Yes & 922 & $38 \%$ & $0.41(0.38,0.44)$ & $2.40(1.86,3.09)$ \\
\hline \multicolumn{5}{|c|}{ Whether primary carer's physical or emotional well-being has changed due to caring role } \\
\hline No & 1,246 & $53 \%$ & $0.20(0.18,0.22)$ & \\
\hline Yes & 1,092 & $47 \%$ & $0.37(0.33,0.40)$ & $1.47(1.12,1.95)$ \\
\hline \multicolumn{5}{|c|}{ Whether primary carer has unmet need for assistance on weekdays } \\
\hline No unmet need & 1,899 & $81 \%$ & $0.24(0.22,0.26)$ & \\
\hline Unmet need & 439 & $19 \%$ & $0.38(0.33,0.43)$ & $1.51(1.12,2.04)$ \\
\hline \multicolumn{5}{|c|}{ Care recipient's high psychological distress } \\
\hline No & 503 & $21 \%$ & $0.13(0.10,0.17)$ & \\
\hline Yes & 536 & $23 \%$ & $0.34(0.30,0.39)$ & $2.26(1.47,3.47)$ \\
\hline Not stated & 1,299 & $56 \%$ & $0.28(0.25,0.31)$ & $2.06(1.31,3.25)$ \\
\hline \multicolumn{5}{|c|}{ Care recipient's long-term conditions } \\
\hline \multicolumn{5}{|l|}{ Cancer } \\
\hline No & 2,236 & $96 \%$ & $0.27(0.25,0.29)$ & \\
\hline Yes & 102 & $4 \%$ & $0.21(0.13,0.31)$ & $1.03(0.54,1.94)$ \\
\hline \multicolumn{5}{|l|}{ Endocrine } \\
\hline No & 1,808 & $77 \%$ & $0.26(0.24,0.28)$ & \\
\hline Yes & 530 & $23 \%$ & $0.28(0.23,0.32)$ & $1.00(0.69,1.44)$ \\
\hline \multicolumn{5}{|l|}{ Psychological } \\
\hline No & 1,344 & $58 \%$ & $0.22(0.20,0.24)$ & \\
\hline Yes & 994 & $42 \%$ & $0.33(0.30,0.36)$ & $0.98(0.76,1.26)$ \\
\hline \multicolumn{5}{|l|}{ Cardiovascular } \\
\hline No & 1552 & $66 \%$ & $0.27(0.25,0.28)$ & \\
\hline Yes & 786 & $34 \%$ & $0.27(0.20,0.35)$ & $1.00(0.75,1.33)$ \\
\hline \multicolumn{5}{|c|}{ Musculoskeletal } \\
\hline No & 1,370 & $59 \%$ & $0.27(0.25,0.30)$ & \\
\hline Yes & 968 & $41 \%$ & $0.25(0.22,0.28)$ & $1.47(1.07,2.02)$ \\
\hline \multicolumn{5}{|l|}{ Congenital } \\
\hline No & 2,243 & $96 \%$ & $0.26(0.24,0.29)$ & \\
\hline Yes & 95 & $4 \%$ & $0.27(0.25,0.30)$ & $0.54(0.31,0.96)$ \\
\hline \multicolumn{5}{|c|}{$\begin{array}{l}\text { Unclassifiable symptoms and signs (eg physical restrictions, memory problems or receiving care } \\
\text { for undetermined conditions) }\end{array}$} \\
\hline No & 2,116 & $91 \%$ & $0.26(0.25,0.28)$ & \\
\hline Yes & 222 & $9 \%$ & $0.28(0.22,0.36)$ & $1.08(0.70,1.67)$ \\
\hline
\end{tabular}

aOR, adjusted odds ratio; $\mathrm{Cl}$, confidence interval

*Adjusted odds ratios with 95\% confidence intervals for variables significantly associated with high psychological distress $(P$ value $<0.05)$ are highlighted in bold. 